\title{
Pheochromocytoma Crisis During Routine Hysterectomy: A Case Report and Clinical Review
}

\author{
Chase M Donaldson ${ }^{1 *}$, Luke J Meininger ${ }^{2}$ and Geoffrey C Chin ${ }^{3}$ \\ ${ }^{1}$ Department of Pulmonary and Critical Care, William Beaumont Army Medical Center, USA \\ ${ }^{2}$ Department of Medicine, William Beaumont Army Medical Center, USA \\ ${ }^{3}$ Department of Endocrinology, William Beaumont Army Medical Center, USA
}

Submission: August 12, 2019; Published: August 27, 2019

*Corresponding author: Chase M Donaldson, Department of Pulmonary and Critical Care, William Beaumont Army Medical Center, USA

\begin{abstract}
Pheochromocytoma crisis is an acute catecholamine-induced hemodynamic instability causing end-organ dysfunction, often provoked by surgery or medications. During surgery, undiscovered pheochromocytomas presenting in crisis carries an $80 \%$ mortality rate. We present a patient who developed pheochromocytoma crisis after receiving metoclopramide during a hysterectomy. Acute, preoperative, and perioperative management of pheochromocytoma crisis is discussed.
\end{abstract}

Keywords: Endocrinology; Adrenal tumors; Perioperative care; Critical care

Abbreviations: PHEO: Pheochromocytoma; PCC: Pheochromocytoma Crisis

\section{Introduction}

Pheochromocytoma (PHEO) is a rare, catecholamine-secreting neuroendocrine tumor of the adrenal medulla. It is present in $0.2-$ $0.6 \%$ of hypertensive patients [1]. The average time to diagnosis is 3 years and it is incidentally found in $0.05-0.1 \%$ of autopsies [2]. With paragangliomas, the prevalence is $1.5-1.6$ per 10,000 patients and $10 \%$ of patients remain asymptomatic [3].

Pheochromocytoma crisis (PCC) presents as acute hemodynamic instability leading to end-organ dysfunction or damage [4]. PCC can be provoked by surgery, medications, or physiological changes (e.g., pregnancy) [5]. During surgery, laryngoscopy, intubation, peritoneal insufflation, diathermy, and tumor manipulation can stimulate catecholamine release $[6,7]$. Medication classes that can stimulate or exacerbate catecholamine action include corticosteroids, opioids, sympathomimetics, vagolytics, histamine-releasing agents, antidepressants, dopamine antagonists, glucagon, and neuromuscular blocking agents $[6,8]$. Resultingly, undiagnosed pheochromocytoma presenting with hemodynamic crises during surgery carries an $80 \%$ mortality rate [9].

\section{Case Description}

A 50-year-old female with a 2-year history of hypertension, anxiety, and migraines underwent robotic hysterectomy for fibroids. On later questioning, she also endorsed paroxysmal palpitations. Her outpatient medications were propranolol, amlodipine, rizatriptan, and omeprazole. Induction occurred uneventfully with fentanyl, lidocaine, propofol, succinylcholine, and phenylephrine. Most of the case proceeded without incident, even during peritoneal insufflation and conversion to open procedure due to the size of the uterus. About 3 hours into the procedure, she received atropine, ketamine, desflurane, and metoclopramide, developing an acute rise in systolic blood pressure to $180 \mathrm{mmHg}$ and decrease in heart rate to 50 . Every few minutes, her systolic pressures ranged from 80 to 260 and heart rate ranged from 50 to 110 in a sinus rhythm. She received propofol, esmolol, metoprolol, dexmedetomidine, and fluid boluses. Malignant hyperthermia was ruled out based on absence of fever or elevated end-tidal $\mathrm{CO}_{2}$.

After surgery, she remained intubated and was transferred to the intensive care unit, where she remained hemodynamically unstable overnight. Her systolic pressure ranged from 80 to 320 , with heart rate dropping to as low as 30 during hypertensive episodes. She received alternating drips of nicardipine and epinephrine. CT imaging of the head ruled out intracranial bleed and Cushing reflex. Despite having dynamic T-wave changes in the lateral leads, cardiac enzymes were negative. Chest radiograph ruled out pulmonary edema. She had hyperglycemia (glucose $230 \mathrm{mg} / \mathrm{dL}$ ) and a post-operative ileus. Other workup revealed 
normal lactate, thyroid function tests, hepatic enzymes, and renal function.

Non-contrast CT imaging of the abdomen and pelvis revealed a $5.3 \times 5.1 \times 4.7 \mathrm{~cm}$ inhomogeneous right adrenal mass with 45 Hounsfield units. Biochemical testing for pheochromocytoma is summarized in Table 1. She was discharged on phenoxybenzamine, which resolved her daily migraines.

She had repeat biochemical testing and a Metaiodobenzylguanidine scan, which revealed focal increased uptake within the right adrenal mass. She restarted amlodipine and liberalized her salt intake. Later, she started propranolol to control her tachycardia. Due to patient preference, she underwent adrenalectomy 10 weeks after initial presentation. She was preadmitted 2 days prior to surgery to optimize blood pressure, heart rate, and intravascular volume. Up until surgery she was taking phenoxybenzamine $20 \mathrm{mg}$ twice daily, amlodipine $5 \mathrm{mg}$ daily, and propranolol 20mg three times daily.

During the laparoscopic adrenalectomy, there were 2 episodes with systolic pressure of 220 and heart rate up to 125 during positioning and peritoneal insufflation. Each episode was treated nicardipine, nitroprusside, and esmolol. She was monitored for 2 days postoperatively before being discharged symptom-free and normotensive. At follow up, pathology confirmed benign pheochromocytoma and biochemical testing was negative.

\section{Discussion}

Prompt recognition and treatment of PCC is vital to patient survival. A high degree of suspicion is needed, as PCC can mimic acute coronary syndrome, cardiogenic shock, hypertensive crisis, stroke, intracranial bleed, pulmonary edema, septic shock, preeclampsia, medication reaction, and malignant hyperthermia $[4,6]$. Current guidelines do not address management of PCC, so Whitelaw et al developed a method to categorize PCC according to severity [4]. Type A crises present with hemodynamic instability and end-organ dysfunction or damage of at least one system, whereas Type B crises present with sustained shock and multiorgan dysfunction or damage [4]. Our patient had Type A crisis, due to hemodynamic instability, arrythmias, dynamic T-wave changes, hyperglycemia, and ileus.

Patients in PCC should have invasive arterial blood pressure monitoring and central venous access. In severe crises, pulmonary artery catheterization or echocardiography may be necessary to assess for volume status and evidence of cardiomyopathy. Shortacting IV vasodilators, such as nicardipine, sodium nitroprusside, hydralazine, fenoldopam, and phentolamine [4,6], are effective for acute hypertension. Magnesium sulfate can be a helpful adjunct to vasodilators and can treat ventricular tachyarrhythmias $[4,7]$. Due to volume contraction from chronic vasoconstriction, patients can develop hypotension when receiving vasodilators [4]. Hypotension is primarily treated with judicious amounts of intravenous fluids. In case of refractory hypotension, vasopressin may be a preferred pressor, although dopamine, norepinephrine, and phenylephrine have been used $[4,6,7]$. Tachyarrythmias can be treated with the selective $\beta 1$-blocker, esmolol, after receiving $\alpha$-blockade [4,6]. Labetalol should be avoided [4]. Patients in profound shock may require extra-corporeal life support or cardiopulmonary bypass [6].

When possible, collect plasma and 24-hour urine measurements of metanephrines and catecholamines. Results will not be available immediately and there are no guidelines for biochemical diagnosis of PHEO in the acute setting. However, some series of PCC report catecholamines around 23 times and metanephrines around 12 times the upper limits of normal, respectively $[4,10]$. CT imaging is effective in localizing the tumor, as more than $95 \%$ of paragangliomas and pheochromocytomas are the abdomen and pelvis [2]. PHEOs are usually well circumscribed, maybe cystic with necrotic or hemorrhagic regions, are more than 10 Hounsfield units on non-contrast images and show marked post-contrast enhancement [11].

Once stabilized, the patient should transition to oral $\alpha$-blockers, such as phenoxybenzamine, or the selective $\alpha 1$-blockers doxazosin, terazosin, or prazosin. The dihydropyridine calcium channel blockers nifedipine and amlodipine are useful adjuncts to $\alpha$-blockers and may prevent coronary vasospasm $[6,8]$. Patients should liberalize their salt intake to replete their intravascular volume. After treatment with $\alpha$-blockers, $\beta$-blockers can be added. Selective $\beta 1$-blockers, such as atenolol and metoprolol, may be preferred over nonselective blockers [6]. Preoperative control is achieved when blood pressure is less than $130 / 80$ seated without tachycardia or orthostatic signs [1]. Many patients who survive PCC may be discharged home for optimization prior to adrenalectomy [10]. Patients with PHEO are typically prepared with $\alpha$-blockers at least 1-2 weeks prior to surgery, but there are situations when urgent adrenalectomies have been performed $[4,10]$. Relevant outpatient medications to avoided are dopamine blockers (antipsychotics, antiemetics), sympathomimetics (decongestants, stimulants, anorexigens, bronchodilators), $\beta$-blockers (without prior $\alpha$-blockade), and certain antidepressants (tricyclics, monoamine oxidase inhibitors, and rarely selective serotonin reuptake inhibitors) [6]. Other substances implicated in adverse events are vagolytics, histamine-releasing opiates, corticosteroids, ACTH, glucagon, and nicotine [6]. Metoclopramide is well known for causing catastrophic reactions in patients with PHEO and was used as a provocative agent in its diagnosis [6]. Interestingly, the patient received succinylcholine and phenylephrine during her first surgery, but did not develop PCC until receiving atropine, ketamine, desflurane, and metoclopramide.

Anesthesia for PHEO is challenging and should be coordinated with the Endocrinologist and Surgeon. Invasive arterial and central venous pressure monitoring are recommended for all patients, while those with cardiomyopathy may need intraoperative trans-esophageal echocardiography or pulmonary artery catheterization $[7,8]$. Prior to induction, anxiolytics reduce 
anxiety, but metoclopramide and prochlorperazine should be avoided [8]. Propofol and etomidate are commonly used during induction, whereas ketamine should be avoided [7]. Vecuronium is widely used as a neuromuscular blocker, but succinylcholine may provoke catecholamine release during fasciculation and pancuronium may reduce parasympathetic tone [7]. Sevoflurane, isoflurane, and nitrous oxide can be used for inhalational anesthesia, but desflurane should be avoided [7]. Compared to morphine, fentanyl and its derivatives cause minimal release of histamine [6]. Coordination with the surgeon during the operation can alert the anesthesiologist to potential catecholamine release. Management of hemodynamic changes during surgery is similar to that of PCC. Hypotension can result from vasodilation, persistent $\alpha$-blockade, anesthesia, hypovolemia, or after tumor ligation [6]. Prior to tumor ligation, discontinuation of vasodilators and administration of fluid can prevent hypotension [7]. After the operation, patients should be monitored for 1-2 days for hypoglycemia, hemodynamic instability, and changes in fluid status.

\section{Conclusion}

Pheochromocytomas are rare catecholamine-secreting tumors that can escape detection. When provoked by medications or surgery, these tumors can lead to catastrophic crises characterized by hemodynamic instability and organ dysfunction. Acute management of pheochromocytoma crises requires high level of suspicion and treatment in the intensive care setting. Once stabilized, patients should be diagnosed and prepared for tumor resection with vasodilators, volume expansion, and control of tachyarrhythmias. Perioperatively, coordination between the anesthesiologist and surgeon can mitigate hemodynamic changes during each step. Postoperatively, patients should be monitored for dysglycemia, hemodynamic instability, and volume status (Table 1).

Table 1: Biochemical Testing for Pheochromocytoma.

\begin{tabular}{|c|c|c|c|c|}
\hline Lab & During Crisis $^{\mathrm{a}}$ & After Discharge $^{b}$ & After Resection ${ }^{c}$ & Reference Range \\
\hline Urine Metanephrine & $546 \mathrm{mcg} / 24$ hours & $372 \mathrm{mcg} / 24$ hours & $56 \mathrm{mcg} / 24$ hours & $45-290 \mathrm{mcg} / 24$ hours \\
\hline Urine Normetanephrine & $8848 \mathrm{mcg} / 24$ hours & $7440 \mathrm{mcg} / 24$ hours & $341 \mathrm{mcg} / 24$ hours & $82-500 \mathrm{mcg} / 24$ hours \\
\hline Urine Epinephrine & $32 \mathrm{mcg} / 24$ hours & & $1 \mathrm{mcg} / 24$ hours & $0-20 \mathrm{mcg} / 24$ hours \\
\hline Urine Norepinephrine & $178 \mathrm{mcg} / 24$ hours & & $33 \mathrm{mcg} / 24$ hours & $0-135 \mathrm{mcg} / 24$ hours \\
\hline Urine Dopamine & $148 \mathrm{mcg} / 24$ hours & & $125 \mathrm{mcg} / 24$ hours & $0-510 \mathrm{mcg} / 24$ hours \\
\hline Plasma Metanephrine & $127 \mathrm{pg} / \mathrm{mL}$ & $69 \mathrm{pg} / \mathrm{mL}$ & & $0-62 \mathrm{pg} / \mathrm{mL}$ \\
\hline Plasma Normetanephrine & $5281 \mathrm{pg} / \mathrm{mL}$ & $3317 \mathrm{pg} / \mathrm{mL}$ & & $0-145 \mathrm{pg} / \mathrm{mL}$ \\
\hline Plasma Epinephrine & $125 \mathrm{pg} / \mathrm{mL}$ & $98 \mathrm{pg} / \mathrm{mL}$ & & $0-62 \mathrm{pg} / \mathrm{mL}$ \\
\hline Plasma Norepinephrine & $1457 \mathrm{pg} / \mathrm{mL}$ & $1330 \mathrm{pg} / \mathrm{mL}$ & & $0-874 \mathrm{pg} / \mathrm{mL}$ \\
\hline Plasma Dopamine & $34 \mathrm{pg} / \mathrm{mL}$ & $<30 \mathrm{pg} / \mathrm{mL}$ & & $0-48 \mathrm{pg} / \mathrm{mL}$ \\
\hline Urine Vanillylmandelic Acid & $12.5 \mathrm{mg} / 24$ hours & & & $0-10 \mathrm{mg} / 24$ hours \\
\hline
\end{tabular}

aDrawn during pheochromocytoma crisis. Urine normetanephrine and plasma normetanephrine were 17.7 and 36.4 times the upper limit of normal, respectively.

bDrawn 9 days later, as an outpatient.

'Drawn after resection of pheochromocytoma.

\section{Conflicts of Interest}

The conclusions in this manuscript are of the authors' alone and do not reflect those of William Beaumont Army Medical Center, AMEDD, Department of Defense, or the US Army.

\section{References}

1. Lenders JW, Duh QY, Eisenhofer G, Gimenez Roqueplo AP, Grebe SK, et al. (2014) Pheochromocytoma and Paraganglioma: An Endocrine Society Clinical Practice Guideline. J Clin Endocrinol Metab 99(6): 1915-1942.

2. Lenders JWM, Eisenhofer G (2017) Update on Modern Management of Pheochromocytoma and Paraganglioma. Endocrinol Metab (Seoul) 32(2): 152-161.
3. Young WF, Calhoun DA, Lenders JWM, Stowasser M, Textor SC (2017) Screening For Endocrine Hypertension: An Endocrine Society Scientific Statement. Endocr Rev 38(2): 103-122.

4. Whitelaw BC, Prague JK, Mustafa OG, Schulte KM, Hopkins PA, et al. (2014) Phaeochromocytoma Crisis. Clin Endocrinol 80(1): 13-22.

5. Guillemot J, Compagnon P, Cartier D, Thouennon E, Bastard C, et al. (2009) Metoclopramide Stimulates Catecholamine- And GraninDerived Peptide Secretion from Pheochromocytoma Cells Through Activation of Serotonin Type 4 (5-Ht4) Receptors. Endocr Relat Cancer 16(1): 281-290.

6. Eisenhofer G, Rivers G, Rosas AL, Quezado Z, Manger WM, et al. (2007) Adverse Drug Reactions in Patients With Phaeochromocytoma: Incidence, Prevention And Management. Drug Saf 30(11):1031-1062.

7. Ramakrishna H (2015) Pheochromocytoma Resection: Current Concepts in Anesthetic Management. J Anaesthesiol Clin Pharmacol 31(3): 317-323.s

8. Azadeh N, Ramakrishna H, Bhatia NL, Charles JC, Mookadam F (2016) Therapeutic Goals in Patients With Pheochromocytoma: A Guide To Perioperative Management. Ir J Med Sci 185(1): 43-49. 
9. O’Riordan JA (1997) Pheochromocytomas and Anesthesia. Int Anesthesiol Clin 35(4): 99-127.

10. Scholten A, Cisco RM, Vriens MR, Cohen JK, Mitmaker EJ, et al. (2013) Pheochromocytoma crisis is not a surgical emergency.J Clin Endocrinol Metab 98(2): 581-591.s

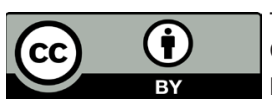

This work is licensed under Creative Commons Attribution 4.0 License

DOI: 10.19080/JAICM.2019.09.555763
11. Kannan S, Purysko A, Faiman C, Remer EM, Shah L, et al. (2014) Biochemical and Radiological Relationships in Patients with Pheochromocytoma: Lessons from a Case Control Study. Clin Endocrinol (Oxf) 80(6): ss790-796.

\section{Your next submission with Juniper Publishers will reach you the below assets}

- Quality Editorial service

- Swift Peer Review

- Reprints availability

- E-prints Service

- Manuscript Podcast for convenient understanding

- Global attainment for your research

- Manuscript accessibility in different formats

( Pdf, E-pub, Full Text, Audio)

- Unceasing customer service

Track the below URL for one-step submission https://juniperpublishers.com/online-submission.php 